\title{
Preventive Behaviors as Correlates of Periodontal Health Status
}

\section{W. Paul Lang, DDS, MPH; David L. Ronis, PhD; Mahassen M. Farghaly, BDS, PhD}

Abstract

Objectives: This investigation examined current practices of brushing, flossing, and periodic dental visits and their association with periodontal health status. Mothods: Data were collected using face-to-face interviews and 40-minute in-home dental examinations with a probability sample of adults 18 years of age or older, having at least one tooth, and living in housing units in the Detroit tricounty area. Complete examinations were performed on 319 individuals. Results: On average, subjects reported brushing their teeth about twice a day. About one-third of the population reported flossing at least once a day. Loss of periodontal attachment was related to frequency of brushing while subjects who exhibited acceptable flossing ability had less plaque and calculus, shallower pocket depths, and less attachment loss. Subjects reporting a periodic dental visit at least once a year had less plaque, gingivitis, and calculus than subjects reporting less frequent visits. In regression analyses, brushing thoroughness, flossing ability and frequency, and dental visit frequency were predictors of lower plaque, gingivitis, and calculus scores. In turn, these scores were predictors of shallower pocket depths and less attachment loss. Conclusions: Brushing, flossing, and periodic dental visits were correlated with better periodontal health. The behaviors appeared to be indirectly related to pocket depth and attachment loss through their associations with plaque, gingivitis, and calculus levels. [J Public Health Dent 1995;55(1):10-17]

Key Words: toothbrushing, flossing, dental checkups, preventive behaviors, dental health.

Personal oral hygiene and periodic professional care remain the actions of choice to prevent periodontal diseases $(1,2)$. The American Dental Association (ADA) recommends that brushing and flossing be performed thoroughly at least once a day, with brushing duration being optimally about three minutes (3). Further, the ADA advises that dental visits should be made on a regular basis. Although the efficacy of these preventive practices has been demonstrated in controlled clinical settings (4-8), there is some question about the consequences of these behaviors as they are performed by the general public in "natural" settings $(1,9)$. The purpose of this study was to examine the effects of toothbrushing, flossing, and periodic dental visits as normally performed by lay persons upon their periodontal health status. The effects of these behaviors remain unclear despite four decades of research.

The capability of toothbrushing to remove plaque and control gingivitis is established (10). Complete mechanical tooth cleaning at intervals longer than 48 hours is insufficient to maintain gingival health (11). Recent research has found daily brushing to be nearly ubiquitous, with over 90 percent of the population performing this behavior (12). Further, females are more likely to brush daily as are those individuals with more education and higher income (12-14). Little improvement in periodontal health appears to be gained by brushing more than two times per day $(15,16)$. In a recent study of older adults (17), frequency of toothbrushing was not found to be associated with attachment loss. It has been suggested that quality of brushing may be a more important feature than frequency $(9,15)$. Sociodemographic factors also are associated with oral health status. For example, social class and sex are more strongly associated with oral hygiene and gingival health than toothbrushing (18).

The effectiveness of dental floss in reducing gingivitis and interproximal bleeding has been demonstrated under controlled circumstances $(4,19)$. In a community-based investigation, lower mean attachment loss was noted in independently living older adults who reported flossing at least once a day than those flossing less (17). Flossing effectiveness is decreased with interproximal recession (16), and the potential for tissue damage has been noted in young children who floss (20). The additional benefit of flossing beyond toothbrushing has been questioned $(15,21)$, and some have suggested that not all persons need to perform interdental cleaning to maintain periodontal health (1). Historically, flossing has been practiced by few individuals; however, use has slowly increased with women and the more educated being more frequent flossers $(9,22)$. In a recent investigation (12), nearly one-third of adults reported flossing on a daily basis.

Persons who regularly attend the dental office generally have better periodontal health status (less attachment loss) than infrequent attenders $(17,23,24)$, although risk factors for periodontal disease are observed in regular attenders (25). Understanding the necessary frequency of preventive visits for heal th maintenance has been suggested as a worthy research question (15). Intervals of two to three months prevent the progression of periodontal disease (5), yet such frequency is clearly not practical. The absence of scientific support for biannual visits has been noted (15), yet frequent

Send correspondence and reprint requests to Dr. Lang, School of Dentistry, University of Michigan, 3349 Dental Building, Ann Arbor, MI 48109-1078. Internet: wplangeumich.edu. Dr. Ronis is at the Institute for Social Research and School of Nursing, University of Michigan, and with the Health Services Research and Development Program, Department of Veterans Affairs, in Ann Arbor. Dr. Farghaly is at King Abdul Aziz University in Jeddah, Saudi Arabia. Manuscript received: 6/10/93; returned to authors for revision: 12/28/93; accepted for publication: 7/6/94. 
usage of this visitation schedule persists despite recommendations that schedules be tailored to individuals (3). At the extreme are populations never exposed to prevention or treatment programs that develop little periodontal disease (26). Thus, the optimal frequency of dental visits can vary considerably and depend upon patient characteristics (15).

Understanding about the effectiveness of personal and professional preventive activities on oral health is best described by Gift (9), who observes that associations between performance of these measures and levels of oral health are ambiguous. To that end, our investigation focused on some of these ambiguities by examining the relationship of periodontal health status to brushing, flossing, and periodic dental visits. Specifically, we wished to assess the relationships of frequency and thoroughness of brushing, frequency and ability of flossing, and frequency of dental visits to levels of plaque, gingivitis, and calculus, pocket depths, and loss of periodontal attachment. Additionally, associations of periodontal health status with demographic and socioeconomic factors were examined.

\section{Methods}

Subjects for this study were individuals who consented to a dental examination as part of a multiphase research project on brushing, flossing, and obtaining dental checkups. Phase one involved hour-long, face-to-face interviews of a probability sample of adults 18 years of age or older, having at least one tooth, and living in housing units in the Detroit tricounty area. Sampling was accomplished using stratified, clustered area probability sampling techniques based on census tracts, giving each housing unit (e.g., single-family house, apartment, and mobile home) an equal probability of selection. One randomly selected eligible adult was interviewed from each selected housing unit. Interviews were conducted by 32 professional interviewers who made unlimited visits to the selected housing units at various times to maximize completion of the interviews. An advance mailing was performed to alert subjects to the impending interview. If telephone numbers were known, subjects were called to arrange visits. Additional letters urging participation were sent to pro- spective respondents based on the apparent reason for not participating or subgroup membership (old, young, busy). The response rate for phase one was 72 percent; 662 interviews were completed. The reasonable response rate and comparisons with 1990 census data (12) suggest respondents were generally representative of the defined population.

Demographic variables of age, sex, and race were collected along with two socioeconomic variables: income and education level. Brushing, flossing, and dental checkup frequencies were determined by asking subjects how often they performed these activities. At the time of the interview, subjects were invited to participate in a second phase that consisted of a 40 minute, in-home dental examination, observation of their personal oral hygiene activities, and a brief interview. Subjects were paid $\$ 15$ if they completed the examination.

Informed consent was obtained from all participants who agreed to be examined, and a brief medical history was taken at the beginning of the examination. Subjects were asked about any current treatment by a physician, reasons for treatment, use of prescription and nonprescription medications, and tobacco habits. A variety of health conditions prevented the acquisition of complete examinations on all subjects. Dental examinations were performed using available seating and head lamps. Plaque, gingivitis, calculus, pocket depths, and loss of periodontal attachment (LPA) were measured on the six teeth specified by Ramfjord (27); four sites (mesial-buccal, midbuccal, distal-buccal, and lingual) were probed on each tooth. Plaque and gingivitis were assessed using the plaque and gingival indices $(28,29)$. Calculus was measured according to scoring criteria and methods of Ramfjord (30). Pocket depth and LPA were measured using a $\mathrm{Hu}$ Friedy \#11 probe. Pocket depth was measured in millimeters from the free gingival margin to the base of a pocket. The distance from the free gingival margin to the cementoenamel junction (CEJ) also was measured. The difference between pocket depth and the latter measurement was considered loss of periodontal attachment. The extent and severity index (31) was calculated for the sample using the percent of sites with 2 millimeters or more of attachment loss. Five examiners were trained and calibrated in the several indices using written and visual criteria. Interexaminer percent agreement on attachment loss (within \pm 1 $\mathrm{mm}$ ) ranged from 87 percent to 94 percent; kappas ranged from 0.37 to 0.62 . Intraexaminer percent agreement ranged from 94 percent to 97 percent; kappas were 0.66 to 0.84 . Kappas were within ranges observed in a recent US national survey (32).

Selected home care behaviors-including the length of brushing time, the thoroughness of brushing, and flossing ability - were observed by examiners. Brushing time was measured in seconds using stopwatches. Brushing thoroughness was measured using a modification of brushing measures of Nikias (33). Brushing thoroughness was measured as appropriate toothbrush placement in six maxillary and six mandibular segments of the mouth during toothbrushing. Each arch was divided into three facial and three lingual segments. Each section was scored for acceptable brush placement (score $=1$ ) or unacceptable placement (score $=0$ ). The percent of sites with acceptable brush placement was used as a summary score (range $=0-100$ ). Flossing ability was measured using a modification of the flossing dexterity index (20). Subjects were asked to demonstrate their flossing ability in an anterior and a posterior segment of the mouth. The two sites were assessed using five criteria: holds floss/floss holder firmly, eases floss through contact points, pushes floss subgingivally, wraps floss around line angles, and moves floss vertically against tooth. The criteria were scored as acceptable (score $=1$ ) or unacceptable (score $=0$ ). A summary score (range $=0-100$ ) was constructed by dividing a patient's sum of acceptable scores by the total number of criteria ( 2 sites $\times 5 \mathrm{cri}$ teria $=10$ ) and multiplying by 100 .

Data Analysis. Measures of acceptable brushing and flossing behaviors were developed from responses to several questions from the initial interview. To be considered as having acceptable brushing behavior, a subject had to report (1) brushing at least once daily during the past year, (2) brushing all his or her teeth, and (3) usually brushing parts of the teeth that do not show when smiling. A subject who did not report performing all three aspects of brushing was considered to have 
unacceptable brushing behavior (coded 1 for analyses); reporting performance of all aspects was considered acceptable (coded 2). For acceptable flossing behavior, a subject had to (1) floss at least once daily during the past year, and (2) usually floss all of his or her teeth. A subject who did not report performing these two aspects of flossing was considered to have unacceptable flossing behavior (coded 1); reporting performance of these aspects was considered acceptable (coded 2).

Checkups were defined for subjects as "... visits to a dental office or clinic made not because of any dental problem." Subjects were then asked whether they had ever had a checkup, and how often they had gone to a dentist or dental clinic for a checkup during the past five years. Responses were dichotomized as subjects who had checkups less than once a year or never (coded 1) or had checkups at least once a year (coded 2).

Selected behaviors assessed in phase two were dichotomized for analysis. Median splits were used to dichotomize the number of times a subject reported brushing in four days (frequent, infrequent), observed brushing time (long, short), and times reported flossing in four days (frequent, infrequent). As most subjects could demonstrate reasonable brush placement, brushing thoroughness was dichotomized rather stringently. Observed thoroughness was considered acceptable if brush placement was proper in all 12 mouth segments. Observed flossing ability was considered acceptable if the subject's summary score was greater than or equal to the median score of 80 (range $=0$ 100). Bivariate relationships of the dichotomized preventive behaviors to the five periodontal heal th status measures were assessed using the $t$-test. For all analyses, significance level was set at $P<.05$.

Forward stepwise linear regression was used to identify relationships between the independent variables-demographic measures, socioeconomic measures, preventive behaviors - and each of the five dependent periodontal measures. Analyses were performed in two stages. Demographic, socioeconomic, and behavioral variables were entered into models for plaque, gingivitis, and calculus scores as predictors. Then, models for pocket depth and attachment loss were constructed that included and excluded plaque, gingivitis, and calculus scores. Inclusion and exclusion models were performed because the effects of the preventive behaviors appeared to be masked by the inclusion of these scores.

In the regression analyses, sex was coded as male $=1$, female $=2$; race was coded as white $=1$, nonwhite $=2$; income was coded as $<\$ 20,000=1$, $\geq \$ 20,000=2$. Smoking was coded as subject smokes $=1$, or subject does not smoke $=2$. Reported brushing, flossing, and checkup frequencies were coded as previously described. All other measures were entered as continuous variables. Models were identified by performing a series of regression analyses with different combinations of the independent variables. Coefficient estimates in these models were ultimately refined by entering only significant predictor variables from the exploratory series into final regressions, thus maximizing the number of cases available for analysis and hence the precision of the estimates.

\section{Results}

The response rate for the examination phase of the study was 60 percent $(n=397)$. Because of certain health conditions that were encountered, only 319 subjects completed all portions of the examination, while the remainder ( $n=78$ ) completed the noninvasive portions. Analyses of nonresponse bias were performed to determine if there were differences between subjects who consented to be examined $(n=397)$ and those who did not $(n=265)$ and between subjects who received a complete examination $(n=319)$ and those who did not $(n=265+78)$. Table 1 displays the latter comparison. Numbers of subjects in the tables will vary due to missing data. No statistically significant differences were observed between the groups agreeing and those refusing to be examined. A statistically significant difference in mean years of education was observed between subjects who received a complete examination and those who did not. The difference observed in the percent of subjects who had checkups less than once a year was large, but not statistically significant. Only data for subjects who completed all portions of the examination are presented. These subjects must be considered somewhat select based on differences in education.

TABLE 1

Characteristics of Sample by Examination Status

\begin{tabular}{|c|c|c|c|c|}
\hline \multirow[b]{2}{*}{ Characteristic } & \multicolumn{2}{|c|}{ Subjects Not Examined } & \multicolumn{2}{|c|}{ Subjects Examined } \\
\hline & Value & $(n)$ & Value & $(n)$ \\
\hline \multicolumn{5}{|l|}{ Demographic } \\
\hline Mean age & 44.2 & $(341)$ & 43.7 & $(318)$ \\
\hline Percent female & 62.1 & $(343)$ & 55.5 & $(319)$ \\
\hline Percent nonwhite & 18.2 & $(341)$ & 17.4 & $(317)$ \\
\hline \multicolumn{5}{|l|}{ Socioeconomic } \\
\hline Percent income distribution & & $(343)$ & & $(319)$ \\
\hline$<\$ 20,000$ & 22.4 & $(77)$ & 17.6 & (56) \\
\hline$\$ 20,000-\$ 34,999$ & 23.0 & (79) & 21.3 & $(68)$ \\
\hline$\$ 35,000-\$ 50,999$ & 22.7 & $(78)$ & 24.8 & (79) \\
\hline$\geq \$ 51,000$ & 22.2 & (76) & 31.0 & (99) \\
\hline No response/unknown & 9.6 & (33) & 5.3 & $(17)$ \\
\hline $\begin{array}{l}\text { Mean grade of education } \\
\text { completed }\end{array}$ & 13.0 & $(341)$ & 13.4 & $(318)^{*}$ \\
\hline \multicolumn{5}{|l|}{ Preventive behavior } \\
\hline \% reporting acceptable brushing & 85.7 & $(343)$ & 84.0 & $(318)$ \\
\hline \% reporting acceptable flossing & 20.7 & (343) & 21.6 & (319) \\
\hline $\begin{array}{l}\text { \% reporting dental visit at least } \\
1 / \text { year }\end{array}$ & 69.7 & $(343)$ & 76.4 & $(318)$ \\
\hline
\end{tabular}

"ANOVA, $P=.037$; characteristics other than education did not differ between subjects who were and were not examined. 
TABLE 2

Characteristics of Sample

\begin{tabular}{|c|c|c|c|}
\hline Characteristic & $n$ & Value (SD) & Range \\
\hline \multicolumn{4}{|l|}{ Demographic } \\
\hline Mean age & 318 & $43.7(15.9)$ & $19-90$ \\
\hline Percent female & 319 & 55.5 & \\
\hline Percent nonwhite & 317 & 17.4 & \\
\hline \multicolumn{4}{|l|}{ Socioeconomic } \\
\hline Percent income distribution & 319 & & \\
\hline$<\$ 20,000$ & 56 & 17.6 & \\
\hline$\$ 20,000-\$ 34,999$ & 68 & 21.3 & \\
\hline$\$ 35,000-\$ 50,999$ & 79 & 24.8 & \\
\hline$\geq \$ 51,000$ & 99 & 31.0 & \\
\hline No response/unknown & 17 & 5.3 & \\
\hline Mean grade of education completed & 318 & $13.4(2.4)$ & $2-17$ \\
\hline Percent with dental insurance & 317 & 70.3 & \\
\hline \multicolumn{4}{|l|}{ Brushing } \\
\hline Mean number of times reported in 4 days & 318 & $7.2(3.3)$ & $0-25$ \\
\hline Percent reporting at least 1 /day & 319 & 95.9 & \\
\hline Percent reporting acceptable brushing & 318 & 84.0 & \\
\hline Mean observed thoroughness & 318 & $90.4(17.2)$ & $33.3-100$ \\
\hline Mean observed time (seconds) & 318 & $49.7(31.6)$ & $10-241$ \\
\hline \multicolumn{4}{|l|}{ Flossing } \\
\hline Mean number of times reported in 4 days & 246 & $2.4(2.5)$ & $0-16$ \\
\hline Percent reporting at least 1 /day & 319 & 32.9 & \\
\hline Percent reporting acceptable flossing & 319 & 21.6 & \\
\hline Mean observed ability & 246 & $70.6(29.4)$ & $0-100$ \\
\hline \multicolumn{4}{|l|}{ Periodic dental visits } \\
\hline Percent reporting at least 1 /year & 318 & 76.4 & \\
\hline \multicolumn{4}{|l|}{ Health status } \\
\hline Mean plaque score & 319 & $0.57(.43)$ & $0-3$ \\
\hline Mean gingivitis score & 318 & $0.68(.46)$ & $0-3$ \\
\hline Mean calculus score & 319 & $0.29(.46)$ & $0-2.58$ \\
\hline Mean pocket depth & 319 & $2.36(.61)$ & $1.13-5.63$ \\
\hline Mean LPA & 319 & $1.31(1.49)$ & $0-9.5$ \\
\hline Extent of disease & 319 & 30.3 & \\
\hline Severity of disease (beyond $2 \mathrm{~mm}$ ) & 268 & $1.97(1.18)$ & $1.00-8.67$ \\
\hline Mean number of missing teeth & 317 & $3.80(5.63)$ & $0-24$ \\
\hline
\end{tabular}

Table 2 displays the demographic and socioeconomic characteristics, preventive behaviors, and periodontal health status of the study sample. On average, subjects reported brushing their teeth about twice a day. Nearly all subjects reported brushing at least once a day. The mean brushing time was less than a minute. Over 80 percent of subjects reported acceptable brushing behavior. Nearly all subjects (90\%) satisfied the criteria for observed brushing thoroughness. About one-third of the sample reported flossing at least once a day, but only 22 percent satisfied the criteria for accept- able flossing behavior. Of those who said they flossed $(n=246)$, the mean number of times these subjects flossed in four days was 2.4, and their mean flossing ability score was 70.6 . Threequarters of the population reported making periodic dental visits at least once a year. Mean pocket depth was 2.4 millimeters while the mean loss of attachment was 1.3 millimeters. About 30 percent of all sites exhibited attachment loss of 2 millimeters or more. On average, subjects were missing 3.8 teeth.

Table 3 displays the preventive behaviors in relation to the measures of periodontal health status. Frequent brushers had significantly less gingivitis and attachment loss than infrequent brushers. There were no statistically significant differences in the periodontal health measures between those reporting acceptable and unacceptable brushing behavior. Subjects with long brushing times had significantly less plaque than those with short brushing times. Individuals who exhibited thorough brushing had significantly less plaque, gingivitis, and calculus.

Subjects who reported flossing their teeth frequently had significantly less plaque, gingivitis, and calculus, and shallower pocket depths. Subjects who reported flossing at least once a day had less plaque, gingivitis, and calculus. Subjects who exhibited acceptable flossing ability had significantly less plaque and calculus, shallower pocket depths, and less attachment loss. Subjects reporting a dental visit at least once a year had less plaque, gingivitis, and calculus and shallower pockets and less attachment loss. There were no significant differences in periodontal health status between those with and those without dental insurance.

Table 4 shows the regression models for plaque, gingivitis, and calculus. For plaque, there were two demographic predictors: age and race. $\mathrm{Re}-$ gression coefficients for these variables were positive, indicating more plaque with increasing age and with nonwhite race. Education was the only socioeconomic predictor associated with plaque and its coefficient was negative. Thus, more plaque was associated with a lower education level. Smoking demonstrated a positive association with plaque score. Of the preventive behaviors, flossing ability, times flossed in four days, and brushing thoroughness all had negative coefficients, indicating that as these behaviors increased, plaque scores decreased.

For gingivitis, nonwhite race and age were significant independent variables with positive coefficients. Income was a significant socioeconomic variable and had a negative coefficient. Times flossed in four days was the only preventive behavior that emerged as an independent predictor of gingivitis. Its negative coefficient indicated an inverse relation with this measure. Age, nonwhite race, and in- 
TABLE 3

Mean Values for Measures of Periodontal Health Status in Relation to Preventive Behaviors (Standard deviations in parentheses)

\begin{tabular}{|c|c|c|c|c|c|c|}
\hline Characteristic & & Plaque & Gingivitis & Calculus & Pocket Depth & LPA \\
\hline \multicolumn{7}{|l|}{ Brushing } \\
\hline \multicolumn{7}{|l|}{ Times brushed in 4 days } \\
\hline Frequent $(n=178)$ & & $0.54(.38)$ & $0.61(41) \dagger$ & $0.25(.43)$ & $2.33(.61)$ & $1.13(1.2)^{*}$ \\
\hline Infrequent ( $n=139$ ) & & $0.60(.48)$ & $0.77(.51)$ & $0.34(.49)$ & $2.39(.62)$ & $1.48(1.7)$ \\
\hline \multicolumn{7}{|c|}{ Reported brushing behavior } \\
\hline Acceptable $(n=266)$ & & $0.55(.42)$ & $0.66(.46)$ & $0.27(.44)$ & $2.33(.62)$ & $1.29(1.5)$ \\
\hline Unacceptable $(n=51)$ & & $0.64(.49)$ & $0.80(.49)$ & $0.38(.53)$ & $2.49(.58)$ & $1.32(1.4)$ \\
\hline \multicolumn{7}{|l|}{ Brushing time (seconds) } \\
\hline Long $(n=157)$ & & $0.50(.43)^{*}$ & $0.69(.48)$ & $0.26(.45)$ & $2.30(.62)$ & $1.21(1.5)$ \\
\hline Short $(n=160)$ & & $0.62(.43)$ & $0.67(.44)$ & $0.32(.47)$ & $2.40(.60)$ & $1.36(1.4)$ \\
\hline \multicolumn{7}{|l|}{ Observed thoroughness } \\
\hline Thorough $(n=219)$ & & $0.48(.38) \ddagger$ & $0.62(.45) \ddagger$ & $0.22(.42) \ddagger$ & $2.33(.60)$ & $1.32(1.5)$ \\
\hline Not thorough $(n=98)$ & & $0.74(.48)$ & $0.83(.46)$ & $0.45(.51)$ & $2.40(.64)$ & $1.19(1.4)$ \\
\hline \multicolumn{7}{|l|}{ Flossing } \\
\hline \multicolumn{7}{|l|}{ Times flossed in 4 days } \\
\hline Frequent $(n=130)$ & & $0.43(.30) \ddagger$ & $0.57(.42) \dagger$ & $0.16(.27)^{*}$ & $2.25(.47)^{*}$ & $1.08(1.1)$ \\
\hline Infrequent $(n=115)$ & & $0.63(.50)$ & $0.76(.47)$ & $0.29(.48)$ & $2.43(.62)$ & $1.31(1.6)$ \\
\hline \multicolumn{7}{|l|}{ Floss at least 1 /day } \\
\hline Yes $(n=104)$ & & $0.47(.34) \dagger$ & $0.60(.42)^{*}$ & $0.14(.32) \ddagger$ & $2.35(.59)$ & $1.26(1.3)$ \\
\hline No $(n=214)$ & & $0.61(.46)$ & $0.72(.48)$ & $0.36(.50)$ & $2.36(.63)$ & $1.31(1.5)$ \\
\hline \multicolumn{7}{|c|}{ Reported flossing behavior } \\
\hline Acceptable $(n=68)$ & & $0.45(.37)^{*}$ & $0.60(.45)$ & $0.18(.38)^{*}$ & $2.36(.67)$ & $1.32(1.5)$ \\
\hline Unacceptable $(n=250)$ & & $0.59(.44)$ & $0.71(.47)$ & $0.32(.48)$ & $2.35(.60)$ & $1.28(1.4)$ \\
\hline \multicolumn{7}{|l|}{ Observed ability } \\
\hline Acceptable $(n=100)$ & & $0.41(.30) \ddagger$ & $0.60(.38)$ & $0.13(.26) t$ & $2.21(.48) \dagger$ & $0.96(1.0)^{*}$ \\
\hline Unacceptable $(n=146)$ & & $0.60(.46)$ & $0.69(.50)$ & $0.29(.44)$ & $2.41(.59)$ & $1.33(1.5)$ \\
\hline \multicolumn{7}{|c|}{ Dental visits and insurance } \\
\hline Visit at least 1 / year & - & & & & & \\
\hline Yes $(n=243)$ & & $0.51(.38)+$ & $0.63(.43) \ddagger$ & $0.20(.34) \ddagger$ & $2.30(.59)+$ & $1.18(1.3)^{*}$ \\
\hline No $(n=74)$ & & $0.74(.52)$ & $0.88(.54)$ & $0.59(.65)$ & $2.52(.66)$ & $1.64(1.8)$ \\
\hline \multicolumn{7}{|l|}{ Dental insurance } \\
\hline Yes $(n=222)$ & & $0.57(.44)$ & $0.70(.46)$ & $0.29(.47)$ & $2.36(.63)$ & $1.31(1.5)$ \\
\hline No $(n=94)$ & & $0.55(.40)$ & $0.65(.47)$ & $0.29(.44)$ & $2.33(.58)$ & $1.23(1.3)$ \\
\hline
\end{tabular}

*T-test, $<.05$.

$+<.01$.

$\ddagger<.001$.

come were independent predictors of calculus. Observed flossing ability, flossing at least once a day, and self-reported dental checkups were preventive behaviors associated with calculus; all had negative coefficients.

Table 5 shows regression models for pocket depth and loss of attachment that exclude and include the plaque, gingivitis, and calculus measures. With plaque, gingivitis, and calculus scores excluded from the analyses, smoking, nonwhite race, and age were all positive predictors of increased pocket depth. Observed flossing ability and times flossed in four days also were retained as independent variables; both had negative coefficients. For attachment loss, age, smoking, sex, and education were the only predictors in the exclusion model.

When plaque, gingivitis, and calculus measures were included, plaque and gingivitis scores entered the model initially and were positively associated with pocket depth. Smoking was positively associated with pocket depth, and nonwhite race was the only demographic predictor of pocket depth. None of the preventive behaviors entered the model. With attachment loss, age and smoking demon- strated positive associations. Plaque, gingivitis, and calculus scores also were predictors of attachment loss and had positive coefficients. The only preventive behavior retained in the model was brushing thoroughness, and it was positively associated with attachment loss.

\section{Discussion}

The limitations of this research include the lower response rate for participation in the examination phase of the study, the somewhat select nature of examination subjects based on their years of education, and the use of 
TABLE 4

Linear Regression Models for Plaque, Gingivitis, and Calculus

\begin{tabular}{|c|c|c|c|}
\hline Measures & $\begin{array}{c}\text { Standardized } \\
\text { Coefficient }\end{array}$ & $\begin{array}{c}\mathrm{R}^{2} \text { at } \\
\text { Each Step }\end{array}$ & $P$ \\
\hline $\begin{array}{l}\text { Plaque } \\
\text { Intercept }\end{array}$ & 0.8590 & & \\
\hline Observed flossing ability & -0.1606 & 0.1090 & $<.01$ \\
\hline Education & -0.1438 & 0.1641 & $<.05$ \\
\hline Age & 0.2951 & 0.1990 & $<.001$ \\
\hline Race & 0.2049 & 0.2432 & $<.001$ \\
\hline Times flossed in 4 days & -0.1848 & 0.2874 & $<.01$ \\
\hline Observed brushing thoroughness & -0.1620 & 0.3124 & $<.01$ \\
\hline Smoking & -0.1240 & 0.3269 & $<.05$ \\
\hline $\begin{array}{c}\text { Gingivitis } \\
\text { Intercept }\end{array}$ & 0.7525 & & \\
\hline Income & -0.1692 & 0.0499 & $<.01$ \\
\hline Time flossed in 4 days & -0.2318 & 0.0960 & $<.001$ \\
\hline Race & 0.1510 & 0.1127 & $<.05$ \\
\hline Age & 0.1349 & 0.1302 & $<.05$ \\
\hline $\begin{array}{l}\text { Calculus } \\
\text { Intercept }\end{array}$ & 0.9581 & & \\
\hline Observed flossing ability & -0.2262 & 0.1474 & $<.001$ \\
\hline Income & -0.1734 & 0.2321 & $<.01$ \\
\hline Dental visits at least 1 /year & -0.1938 & 0.2703 & $<.001$ \\
\hline Age & 0.2536 & 0.3065 & $<.001$ \\
\hline Race & 0.1883 & 0.3314 & $<.001$ \\
\hline Floss at least 1 /day & -0.1422 & 0.3502 & $<.05$ \\
\hline Smoking & -0.1282 & 0.3661 & $<.05$ \\
\hline
\end{tabular}

many variables acquired by self-report. Further, because the study was cross-sectional rather than longitudinal, causality cannot be inferred by the observed relationships.

The frequencies of brushing, flossing, and periodic dental visits found in this investigation support the trends of increased performance observed over the last few decades $(22,34,35)$. Although daily brushing was found to be nearly ubiquitous, about 16 percent of individuals reported not fulfilling all the criteria for acceptable brushing behavior. When brushing was observed, most subjects demonstrated appropriate toothbrush placement. The mean observed brushing time of this sample was much shorter than the current recommendation of three minutes (3) or the two to three minutes reported by Nikias (33). Although observations occurred in natural settings, the likelihood that an examiner's presence affected performance must be acknowledged. One could surmise that subjects would demonstrate more favorable behaviors when knowingly observed, and this fact may account for the high thoroughness scores. On the other hand, why would brushing times be so short? It could be that the average person actually brushes for less than a minute. Alternatively, it was noted that some persons hurried their brushing because of embarrassment at being observed or because they felt the activity was supposed to be a demonstration of their competence, not their actual behavior. It must be questioned whether unobtrusive observation is possible.

The importance of quality of brushing over frequency of brushing $(9,15)$ was supported by the bivariate analyses. Those who demonstrated more thorough brushing had lower levels of plaque, gingivitis, and calculus, while those with longer brushing times had less plaque. However, less gingivitis and attachment loss also were observed in subjects reporting frequent brushing. Likely, there are many ways to perform adequate plaque removal with a toothbrush. Frequent brushings, one thorough long brushing, or some combination of these actions could accomplish the task. Further analyses of various combinations are warranted.

As for flossing, about one-third of subjects reported performing this behavior on a daily basis although only one-fifth reported meeting all criteria for acceptable performance. Similarly, about one-third of the sample demonstrated acceptable flossing ability. Acceptable and frequent flossing were associated with improved periodontal health status. Less plaque, gingivitis, and calculus were observed in subjects who flossed frequently or demonstrated acceptable ability. Still, few subjects flossed regularly. The disadvantages of flossing have been enumerated, and education and use of alternative interdental cleaners have been suggested as means to encourage interproximal cleaning (36).

Many differences in periodontal health status were observed between those visiting the dental office at least once $a$ year and those who visited less frequently. These findings are consistent with others who report less attachment loss in regular attenders $(17,23,24,37)$. However, one should be cautious about ascribing too much effect to regular attendance as individuals who frequently attend also are liable to be performing appropriate personal oral hygiene behaviors (9). While those with dental insurance are more likely to visit the dentist (38) and ostensibly receive more preventive services, no relation between having dental insurance and improved periodontal health status was found in this investigation.

Overall, the regression analyses highlight the combined effects of demographic factors, socioeconomic factors, and preventive behaviors. Findings from our study corroborate previously observed associations: older persons consistently demonstrate poorer periodontal health than younger persons $(23,25,32)$, women have better periodontal health $(25,32)$, and nonwhites have poorer periodontal health $(24,25,37)$. Smokers also are likely to have poorer periodontal health $(23,37)$. Further, those with more education or higher incomes have better periodontal health $(23,24,37)$. The relationships found among demographic and socioeco- 
TABLE 5

Linear Regression Models for Pocket Depth and Loss of Attachment

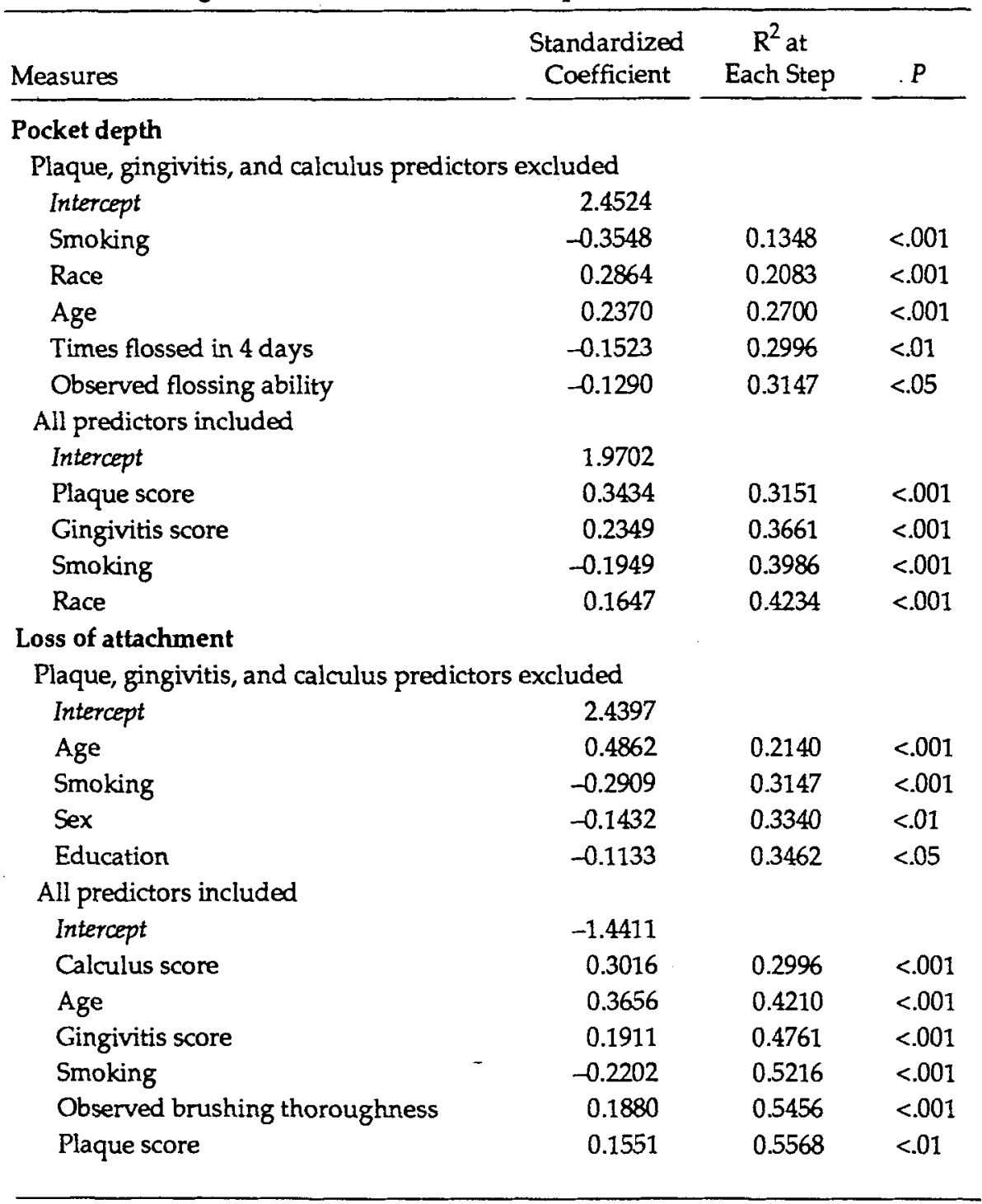

nomic factors and oral hygiene performance also are similar to those reported by others $(9,14)$.

Of the preventive behaviors retained in the models for plaque, calculus, and gingivitis, certain flossing behaviors-frequency and abilitywere often associated with better status. The two behaviors also were inversely associated with increased pocket depth. These findings suggest that flossing contributes to better periodontal health. Alternatively, flossing ability may be an indicator of an individual's propensity to carry out favorable levels of all preventive behaviors. The notion of an individual with consistent patterns of preventive behaviors also is supported by associations between good oral hygiene and diminished periodontal disease ob- served by others (39).

In the inclusion models, plaque and gingivitis measures entered the model for pocket depth while plaque, gingivitis, and calculus entered the model for attachment loss. The flossing behaviors did not enter these models, but may be operating indirectly through the plaque, gingivitis, and calculus measures to affect pocket depth and attachment loss. The positive association of brushing thoroughness and atfor damage to the periodontium by excessive brushing, a possibility proposed elsewhere (40-42).

The associations observed between brushing, flossing, and periodic dental visits and periodontal health status were generally positive. While regur lar, thorough toothbrushing has essentachment loss suggests the potential tially been adopted by most individuals, recommendations about thoroughness may need to be moderated to prevent harm to tissues by some persons. Flossing ability and frequency were linked to better periodontal health, and thus should be encouraged. That few subjects flossed regularly challenges us to develop unique interventions to increase this behavior. Periodic dental visits had positive associations with periodontal health, and most subjects were regular attenders. Reinforcement of this behavior should suffice for most; access issues may need resolution for others. Provider development of preventive regimens also should consider the demographic and socioeconomic factors found to be associated with periodontal health status in this investigation.

\section{Acknowledgments}

This research was supported by NIDR grant DE07800 to David L. Ronis, PhD. The authors thank Kim Krueger for her assistance with data management and analysis.

\section{References}

1. Burt BA. Publichealth implications of recent research in periodontal diseases. J Public Health Dent 1988;48:252-6.

2. Glavind L, Nyvad B. The scientific basis for oral health recommendations for self care. In: Gjermo P, ed. Promotion of self care in oral health. Oslo, Norway: Scandinavian Working Group for Preventive Dentistry, 1986:77-93.

3. American Dental Association. Wake up to prevention for the smile of a lifetime. J Am Dent Assoc 1988;116(Spec Iss):3G, 6G-13G.

4. Finkelstein $P$, Grossman $E$. The effectiveness of dental floss in reducing gingival inflammation. J Dent Res 1979;58:1034-9.

5. Axelsson P. Lindhe J. Effect of controlled oral hygiene procedures on caries and periodontal disease in adults. Results after 6 years. J Clin Periodontol 1981;8 239-48.

6. Finkelstein P, Grossman E. The dinical quantitative assessment of the mechanical cleaning efficiency of toothbrushes. Cin Prev Dent 1984;6:7-12.

7. Bouwsma O, Caton J, Polson A, Espeland M. Effect of personal oral hygiene on bleeding interdental gingiva. Histologic changes. J Periodontol 1988:59:80-6.

8. Finkeistein P, Yost KG, Grossman E. Mechanical devices versus antimicrobial rinses in plaque and gingivitis reduction. Clin Prev Dent 1990:12:8-11.

9. Gift HC. Current utilization patterns of oral hygiene practices. State-of-the-science review. In: Löe $H$, Kleinman DV eds. Dental plaque control measures and oral hygiene practices. Bethesda, MD:IRL Press, 1985:39-71.

10. Walsh M, Heckman B, Leggott P, Armitage $G$, Robertson PB. Comparison of manual and power toothbrushing, with 
and without adjunctive oral irrigation, for controlling plaque and gingivitis. I Clin Periodontol 1989;16:419-27.

11. Lang N, Cumming B, LöeH. Toothbrushing frequency as it relates to plaque development and gingival health. I Periodontol 1973;44:396-405.

12. Ronis DL, Lang WP, Farghaly MM, Passow E. Toothbrushing flossing, and preventive dental visits by Detroit-area residents in relationship to demographic and socioeconomic factors. J Public Health Dent 1993;53:138-45.

13. Murtomaa $\mathrm{H}$. Toothbrushing in Finland. Community Dent Oral Epidemiol 1979;7: 185-90.

14. Chen MS, Stone DB. Toothbrushing, flossing, and dental visits in relation to socioeconomic characteristics of white American families. Community Dent Oral Epidemiol 1983;11:325-32.

15. Frandsen A. Mechanical oral hygiene practices. State-of-the-science review. In: Löe H, Kleinman DV, eds. Dental plaque control measures and oral hygiene practices. Bethesda, MD: IRL Press, 1985:93116.

16. American Academy of Periodontology. Proceedings of the world workshop in clinical periodontics. World Workshop in Clinical Periodontics. Chicago: American Academy of Periodontology, 1989.

17. Locker D, Leake JL. Risk indicators and risk markers for periodontal disease experience in older adults living independently in Ontario, Canada. J Dent Res 1993;72:9-17.

18. Addy $M$, Dummer $P$, Hunter $M$. The effect of toothbrushing frequency, toothbrushing hand, sex and social class on the incidence of plaque, gingivitis and pocketing in adolescents: a longitudinal cohort study. Community Dent Health 1990; 7:237-47.

19. Graves RC, Disney IA, Stamm JW. Comparative effectiveness of flossing and brushing in reducing interproximal bleeding. J Periodontol 1989;60:243-7.
20. Rich SK, Friedman I, Schultz LA. Effects of flossing on plaque and gingivitis in third grade schoolchildren. J Public Health Dent 1989;49:73-7.

21. Burt B, Eklund S. Dentistry, dental practice and the community. 4 th ed. Philadelphia: WB Saunders, 1992.

22. Chen MS, Rubinson L. Preventive dental behavior in families: a national survey. J Am Dent Assoc 1982;105:43-6.

23. Ismail A, Morrison E, Burt B, Caffesse R, Kavanagh M. Natural history of periodontal disease in adults: findings from the Tecumseh periodontal disease study, 1959-87. J Dent Res 1990;69:430-5.

24. Oliver RC, Brown LJ, LöeH. Variations in the prevalence and extent of periodontitis. J Am Dent Assoc 1991;122:43-8.

25. McFall W], Bader JD, Rozier RG, et al. Clinical periodontal status of regularly attending patients in general dental practices. J Periodontol 1989;60:145-50.

26. Löe H, Anerud A, Boysen H, Morrison E. Natural history of periodontal disease in man. Rapid, moderate and no loss of attachment in Sri Lankan laborers 14 to 46 years of age. J Clin Periodontol 1986;13: $432-40$.

27. Ramfjord SP. Indices for prevalence and incidence of periodontal disease. J Periodontol 1959:30:51-9.

28. Silness J, Löe H. Periodontal disease in pregnancy, II. Correlation between oral hygiene and periodontal disease. Acta Odontol Scand 1964;22:121-35.

29. Löe H, Silness J. Periodontal disease in pregnancy, I. Prevalence and severity. Acta Odontol Scand 1963;21:533-51.

30. Ramfjord SP. The periodontal disease index (PDI). J Periodontol 1967;38 (Suppl):602-10.

31. Carlos J, Wolfe M, Kingman A. The extent and severity index: a simple method for use in epidemiologicstudies of periodontal disease. I Clin Periodontol 1986;13: 500-5.

32. Brown LJ, Oliver RC, Löe H. Evaluating periodontal status of US employed adults. J Am Dent Assoc 1990;121:226-32.

33. Nikias MK, Budner NS, Breakstone RS. Maintenance of oral home care preventive practices: an empirical study in two dental settings. J Public Health Dent 1982; 42:7-28.

34. Bureau of Dental Health Education, Bureau of Economic Research and Statistics. Survey of family toothbrushing practices. J Am Dent Assoc 1966;72:1489-91.

35. Craig TT, Montague JL. Family oral health survey. J Am Dent Assoc 1976;92: 326-32.

36. Ronis DL, Lang WP, Farghaly MM, Ekdahl SM. Prevalence of preventive dental behaviors. J Dent Hyg 1994;68:12330.

37. Beck ID, Koch GG, Rozier RG, Tudor GE. Prevalence and risk indicators for periodontal attachment loss in a population of older community-dwelling blacks and whites. J Periodontol 1990;61:521-8.

38. Jack S, Bloom B. Use of dental services and dental health. United States, 1986. Washington, DC: National Center for Health Statistics, 1988; DHHS pub no (PHS) 88-1953. (Vital and heal th statistics; series 10; no 165.)

39. Abdellatif HM, Burt BA. An epidemiological investigation into the relative importance of age and oral hygiene status as determinants of periodontitis. J Dent Res 1987;66:13-18.

40. Sangnes G, Gjermo P. Prevalence of oral soft and hard tissue lesions related to mechanical toothcleaning procedures. Community Dent Oral Epidemiol 1976;4:7783.

41. Niemi M, Sandholm L, Ainamo J. Frequency of gingival lesions after standardized brushing as related to stiffness of toothbrush and abrasiveness of dentifrice. J Clin Periodontol 1984;11:254-61.

42. Löe $H$, Anerud A, Boysen $H$, Smith $M$. The natural history of periodontal disease in man. The rate of periodontal destruction before 40 years of age. J Periodontol 1978;49:607-20.

\section{SCHEDULED DATES OF FUTURE MEETINGS OF THE AMERICAN ASSOCIATION OF PUBLIC HEALTH DENTISTRY}

1995 October $4-6 \ldots . . . \ldots \ldots \ldots . . .$. Las Vegas, $\mathrm{NV}$ 1996 September $25-27 \ldots \ldots \ldots \ldots \ldots$. . . Orlando, FL 1997 October $15-17 \ldots \ldots \ldots \ldots$. . . Washington, DC 1998 October 21-23 .............. San Francisco, CA 